Como citar este artigo: Silva, Y. R. M., Cardoso, M. D., Mulatinho, L. M., Souza, C. F. Q., \& Silva Júnior, W. S. Cobertura de um jornal online sobre dengue em Recife/PE: uma análise de conteúdo. Revista Psicologia, Diversidade e Saúde. 2018;7(1):72-80. doi: 10.17267/2317-3394rpds.

\title{
Cobertura de um jornal online sobre dengue em Recife/PE: uma análise de conteúdo
}

\author{
Coverage of an online journal about dengue in Recife/PE, \\ Brazil: an analysis of content
}

\author{
Yasmin Raisa Melo Silva', Mirian Domingos Cardoso², Letícia Moura Mulatinho², Claudinalle \\ Farias Queiroz de Souza ${ }^{2}$, Walmir Soares da Silva Júnior ${ }^{2}$

\begin{abstract}
'Autora para correspondência. Centro de Pesquisa Aggeu Magalhães - CpqAM Fiocruz PE. Recife, Pernambuco, Brasil. yasmin.raisa@hotmail.com ${ }^{2}$ Faculdade de Enfermagem Nossa Senhora das Graças, Universidade de Pernambuco. Recife, Pernambuco, Brasil.
\end{abstract} \\ mirian.domingos@gmail.com, leticia@mulatinho.net, claudinalle.souza@upe.br, walmir41@gmail.com
}

RESUMO I A dengue se consolidou como um dos maiores desafios de saúde pública dos últimos tempos na cidade do Recife. Esta pesquisa teve por objetivo analisar o conteúdo das notícias sobre dengue em um jornal online de grande influência digital no Recife, PE. Trata-se de um estudo descritivo qualitativo, que utilizou a análise de conteúdo $(\mathrm{AC})$ como método de técnica de organização e de análise dos dados, o período para a busca das reportagens no jornal online foi de janeiro a abril de 2016 e os conteúdos foram agrupados de acordo com as categorias: a) papel das autoridades; b) informação epidemiológica; c) culpabilização da comunidade; d) formas de prevenção e controle do vetor; e) ações educativas promovidas. Durante este mesmo período, foram notificados 13.049 novos casos de dengue, e publicadas 42 notícias sobre a dengue no jornal online, porém apenas seis notícias sobre a doença no município estudado. A partir da análise foi possível observar que as fontes de informação oficiais foram as mais utilizadas pelo jornal, especialmente as fornecidas pela Secretaria Municipal de Saúde. A maioria das notícias narravam o papel das autoridades e informações epidemiológicas, como número de casos notificados, confirmados e os óbitos. Comprovou-se o reduzido número de informações emitidas durante processos epidêmicos, e durante todo o ano. Entretanto, o jornal online divulgou algumas notícias importantes em relação ao número de casos da doença, sendo de grande importância na conscientização da população e para a saúde pública.

Palavras-Chave: Comunicação em Saúde; Dengue; Mídias Sociais.

\begin{abstract}
I The dengue has consolidated itself as one of the biggest challenges of public health of the last times in the city of Recife. This research aimed to annalyse the news contents about dengue in an online journal of a major gifital influence in Recife, PE. It is a qualitative descriptive study, which used content annalysis as the organizational technique method and as data annalysis, the time frame for search of the reports in the online jornal was from January to April of 2016 and the contentes were grouped according to the following categories: a) authorities role; b) epidemiological information; c) community blame; d) prevention means and vetor control; e) promoted educational measures. During this same period, there were 13.049 new cases of dengue on the online jornal, and 42 tidings were published about dengue in the online journal. However, only six tidings were about the disease in the city which was being studied. From the analysis, it was possible to observe that the information sources were more used by the paper, specially the ones offered by the city's health office. The most part of the tidings narrated the authorities role and epidemiological information, as the number of notified and confirmed cases as well as deaths. A maioria das notícias narravam o papel das autoridades e informações epidemiológicas, como número de casos notificados, confirmados e os óbitos. It was proved the reduced number of issued informations during the epidemic processes, and during all year long. However, the online jornal disclosed some important tidings in relation to teh number of cases of the disease, being of great importance to the population awareness and to public health.
\end{abstract}

Keywords: Health Communication; Dengue; Social Media. 


\section{Introdução}

\section{Contextualizando dengue}

Dengue é a doença viral transmitida por mosquito que se espalha mais rapidamente no mundo. Nos últimos 50 anos, a sua incidência aumentou 30 vezes, com aumento da expansão geográfica para novos países e, na presente década, para pequenas cidades e áreas rurais. Estima-se que 50 milhões de infecções por dengue ocorram anualmente, e que aproximadamente 2,5 bilhões de pessoas vivam em países onde a dengue é endêmica (Villela, 2012).

A transmissão da dengue acontece através da picada da fêmea do Aedes aegypti, no ciclo homem - Aedes aegypti - homem. Está intrinsicamente ligada a condições socioambientais que promovem a dispersão do vetor transmissor que se reproduz em locais onde há água parada como, por exemplo, em criadouros artificias (pneus, latas, garrafas, plásticos, vasos de plantas) e acidentalmente criadouros naturais (em poças no solo, bifurcações de troncos e folhas de árvores) (Silva, Mallmann, \& Vasconcelos, 2015).

No Brasil, a Dengue se consolidou como um dos maiores desafios de saúde pública. Ao longo dos últimos anos, foram registrados aproximadamente, 4,8 milhões de casos prováveis da doença (Ministério da Saúde [MS], 2014).

Em 2016, até a 51 a semana epidemiológica, no período de 03/1/2016 a 24/12/2016, foram registrados 1.496 .282 casos prováveis de Dengue no país e outros 712.396 casos suspeitos foram descartados no Brasil (Ministério da Saúde [MS], 2017).

Em Recife, no ano de 2016 até a 52 ${ }^{a}$ Semana Epidemiológica, haviam sido notificados 19.133 casos de Dengue e 10.733 foram confirmados (Secretaria Executiva de Vigilância à Saúde, 2016).

Embora o governo desempenhe grandes esforços na elaboração de estratégias para o enfrentamento do problema, o controle da dengue tem se mostrado de solução complexa, sendo necessário repensar - modo de planejamento e ações para promoção, prevenção e controle vetorial, visto que a transmissão da doença se mantém, com presença de surtos epidêmicos recorrentes nas diversas regiões, como Norte e Nordeste (Santos, Costa e Silva, Cabral, Gonçalves, \& Augusto, 2015).

O esforço conjunto de governos, instituições e população é de extrema importância para impactar o problema desse agravo no país e, nesta perspectiva, compreender como as informações chegam aos indivíduos e às comunidades, como elas circulam, como são interpretadas e apropriadas, torna-se um aspecto fundamental na construção de estratégias de prevenção e controle (Villela \& Natal, 2014).

\section{Os aspectos socioambientais nas epidemias}

Dengue está intrinsicamente ligada a condições socioambientais que promovem a manutenção e dispersão do vetor. $O$ mosquito transmissor se reproduz em locais onde há água parada como, por exemplo, em criadouros artificias (pneus, latas, garrafas, plásticos, vasos de plantas) e acidentalmente criadouros naturais (em poças no solo, bifurcações de troncos e folhas de árvores) (Xavier, 2010).

Por isso, não se pode analisar a dengue somente pela tríade epidemiológica (agente, hospedeiro e ambiente), mas conseguir ultrapassar esta visão e enxergar o fator social da doença. Assim, o vínculo entre o processo social e o processo saúde-doença é dado por processos particulares, que são ao mesmo tempo sociais e biológicos (Villela, 2012).

Devido ao crescimento das cidades, com a falta de planejamento e urbanização, ocorre uma necessidade de acesso a serviços básicos como água, esgoto e coleta de lixo. A população aumenta e se concentra nas grandes cidades favorecendo a transmissão da doença pelo vetor. Outra questão em relação a água, é que devido ao abastecimento irregular ou inexistentes, faz com que a população tenha que estocar água, favorecendo um ambiente propício ao vetor (Xavier, 2010).

Uma pesquisa publicada pelo Instituto Trata Brasil (2014) revelou que, no ranking das 100 maiores cidades brasileiras, o Recife se destaca negativamente com relação aos recursos destinados ao saneamento, ocupando $\circ 69^{\circ}$ lugar no ranking, $83 \%$ da população recebe água tratada, mas menos da metade da cidade (36\%) conta com rede de esgoto. 
A comunicação em saúde e a influência dos meios de comunicação

A comunicação e a mídia são consideradas essenciais na abordagem à saúde, por terem uma abrangência e inserção junto a população, a mídia pode auxiliar de forma positiva a educação em saúde, fortalecendo assim, a saúde pública no campo da comunicação em saúde (Ferreira, 2006). Na Saúde Pública, compreender como as informações chegam aos indivíduos é essencial para construir estratégias de prevenção e controle de doenças, como a dengue (Pimenta, 2008).

Vilella e Natal (2014, p.1010) dizem que "[...] a informação pode ser usada para beneficiar a sociedade e permitir seu desenvolvimento pessoal ou para manipulá-la por meio da distorção do conteúdo abordado."

Então, a comunicação em saúde e a educação hoje são entendidas não mais de forma unidirecional, como transmissão de conhecimentos e informações entre um emissor e um receptor, mas como circulação e significação de signos entre múltiplos emissores e receptores de mensagens. $O$ poder da mídia de informar em grande escala pode contribuir para a emancipação dos cidadãos e sua inserção autônoma na sociedade (França, Abreu, \& Siqueira, 2004).

A velocidade dos acontecimentos e das informações no mundo atual favorece a ampliação da comunicação digital, caracterizada pela dinamicidade e ampliação do alcance da informação, sendo uma ferramenta importante na utilização da educação em saúde. Hoje, a mídia e a comunicação são reconhecidas por favorecer a promoção da saúde e prevenção de doenças e agravos, além de facilitar o autocuidado. Entretanto, é imprescindível que esta comunicação seja acessível a maioria da população (Romano, Cibotto, Velho, \& Lucena, 2015).

De acordo com a Pesquisa Brasileira de Mídia realizada em 2015, 65\% dos jovens e adultos acessam a internet diariamente em busca principalmente, de informações (Secretaria de Comunicação Social da Presidência da República [Secom], 2015).

Diante deste contexto percebe-se que a comunicação e a mídia são consideradas essenciais na abordagem à saúde. No Brasil, existem poucos estudos sobre a relação comunicação, mídia e saúde, sendo este um tema pouco explorado pela saúde pública. Assim, o presente trabalho teve como objetivo analisar o conteúdo das notícias sobre Dengue em um jornal online de grande circulação no nordeste do Brasil.

\section{Método}

Trata-se de um estudo descritivo qualitativo utilizando a análise de conteúdo ( $\mathrm{AC}$ ) como método de técnica de organização e análise dos dados. $O$ estudo descritivo qualitativo pretende descrever os fatos e fenômenos de determinada realidade, preocupando-se com aspectos da realidade que não podem ser quantificados, centrando-se na compreensão e explicação da dinâmica das relações sociais (Gerhardt \& Silveira, 2009).

Segundo Bardin (2009), a análise de conteúdo enquanto método torna-se um conjunto de técnicas de análise das comunicações que utiliza procedimentos sistemáticos e objetivos de descrição do conteúdo das mensagens. A AC se estrutura em três fases, sendo elas, 1) a pré-análise; 2) a exploração do material; 3) o tratamento dos resultados e interpretação.

O levantamento das notícias foi realizado através do portal online do jornal, um dos 3 mais acessados em Recife. $O$ período definido para a busca das reportagens foi dos meses de janeiro a abril de 2016, uma vez que de acordo com o Boletim Epidemiológico 2015, da Secretária de Saúde do Município, esses meses foram os períodos de maior número de notificações de casos prováveis de Dengue, tendo entre março e abril sua maior incidência (Secretaria Executiva de Vigilância à Saúde, 2016). Através do acesso ao jornal online pelo site foram selecionadas as datas de 01 de janeiro de 2016 até 30 de abril de 2016 , todas as notícias que no título ou como etiqueta/rótulo existia a palavra-chave Dengue foram exportadas através do Adobe Acrobat Reader DC versão 2015 .

Os dados das matérias publicadas foram organizados em uma planilha e em um formulário, adaptado da pesquisa de Villela (2012), criando as seguintes 
categorias de variáveis: a) Variáveis administrativas: título, dia, mês, fonte de informação (oficial/não-oficial), dados principais das notícias (assinatura, seção da notícia, tamanho, presença de ilustração ou fotos). b) Categorias de conteúdo: papel das autoridades, informação epidemiológica, culpabilização da comunidade, formas de prevenção e controle do vetor e ações educativas promovidas.

Após catalogar todos os textos, foi realizado o processamento dos dados, que permitiu melhor visualização e leitura. A análise de conteúdo textual e a interpretação dos dados foi realizada através de exaustiva leitura e classificação de categorias de conteúdo de acordo com as perguntas norteadoras mostradas no Quadro 1. Cada pergunta representa uma categoria temática.

Quadro 1. Perguntas elaborados para coleta de dados das notícias veiculadas nos períodos de janeiro a abril sobre Dengue em Recife. Recife, 2017.

\begin{tabular}{|l|l|}
\hline Categoria temática & Perguntas Norteadoras \\
\hline I) Papel das autoridades & $\begin{array}{l}\text { a) Qual a postura das autoridades em relação a } \\
\text { Dengue? }\end{array}$ \\
\hline II) Informações epidemiológicas & b) Divulgação de número de casos de Dengue? \\
\hline III) Culpabilização da comunidade & $\begin{array}{l}\text { c) Houve falas sobre a culpabilização das pessoas } \\
\text { pelos casos de Dengue na cidade? }\end{array}$ \\
\hline IV) Formas de prevenção e controle do vetor & $\begin{array}{l}\text { d) Divulgação sobre as formas de prevenção e } \\
\text { controle do vetor? }\end{array}$ \\
\hline V) Ações educativas promovidas & $\begin{array}{l}\text { e) Realização de ações educativas nas } \\
\text { comunidades? }\end{array}$ \\
\hline
\end{tabular}

\section{Resultados}

Entre janeiro a abril de 2016, o jornal online publicou 42 notícias sobre Dengue, sendo apenas 06 notícias na área geográfica do município estudado. Apenas $15 \%$ das matérias publicadas que são sobre dengue diziam respeito à cidade do Recife, $45 \%$ ao estado de Pernambuco e $40 \%$ eram replicadas de jornais nacionais. Os meses de fevereiro e março apresentaram maior cobertura de notícias sobre a ocorrência de casos de Dengue, como na Figural.

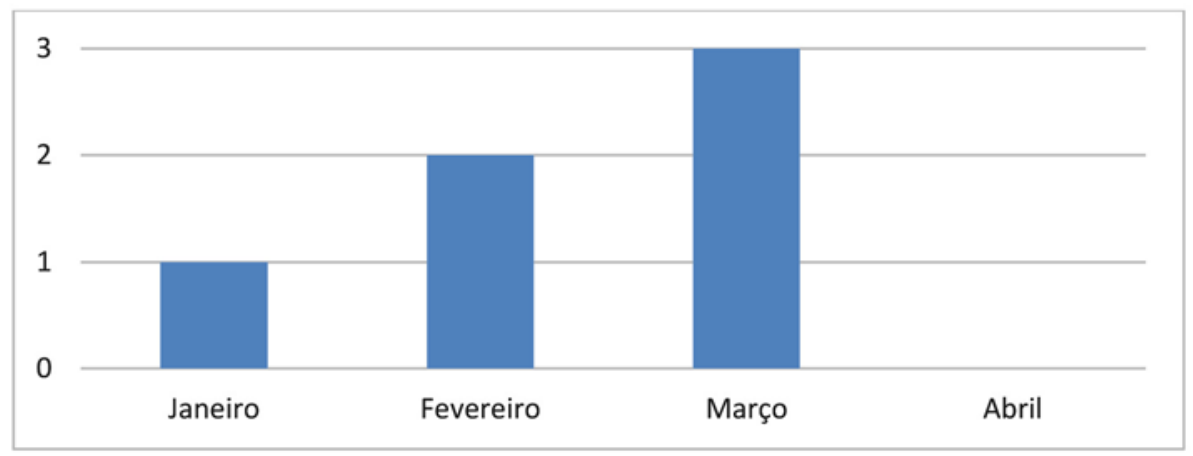

Figura 1. Distribuições das notícias publicadas sobre Dengue em Recife no jornal online de Pernambuco, de acordo com mês de publicação.

As fontes oficiais de informação foram as mais utilizadas pelo jornal no período, especialmente fornecidas pela Prefeitura e pela Secretaria de Saúde do Município. Em apenas uma matéria do tipo editorial, o jornal buscou informações sobre a dengue com a comunidade. Em uma das notícias foram publicados dados da distribuição dos casos notificados pelo município, apontando que no período estudado foram notificados 13.049 casos de Dengue, sendo fevereiro o mês com maior ocorrência Figura 2. 


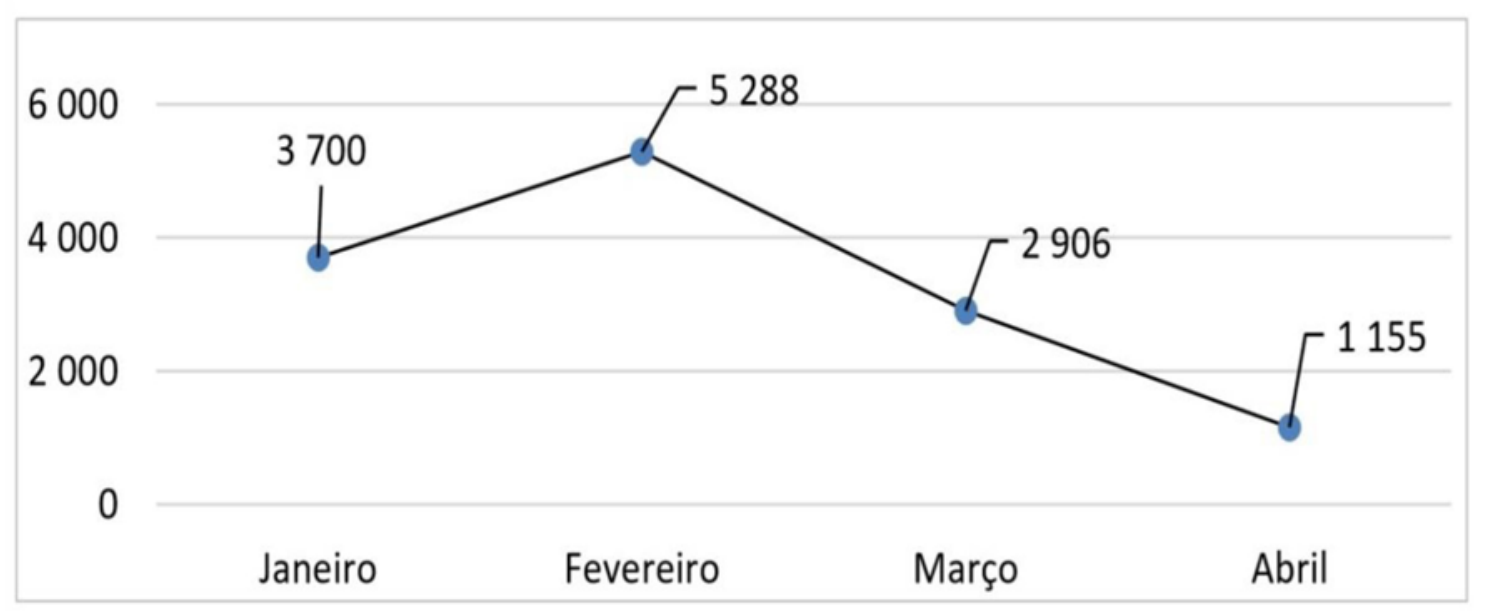

Figura 2. Número de casos Dengue notificados de janeiro a abril de 2016 em Recife, Brasil.

Fonte: Secretaria Executiva de Vigilância à Saúde. (2016). Boletim epidemiológico. Recife. Recuperado de https://cievsrecife.files.wordpress.com/2012/08/boletim-de-arboviroses-se-52-1.pdf

A partir da catalogação das notícias no Quadro 2, na coluna de dados principais da notícia (autor, coluna da notícia, número de páginas, presença de ilustração), foi possível observar que, as duas notícias (N4 e N6), referentes divulgação das ações de educação em saúde em relação a dengue, apresentaram menor destaque no jornal, pois ocuparam um espaço menor que uma página e não possuíam imagens ou ilustrações.

Quadro 2. Notícias sobre Dengue em Recife selecionadas de um jornal online de Pernambuco veiculadas nos períodos de janeiro a abril. Recife, 2017.

\begin{tabular}{|c|c|c|c|c|}
\hline $\begin{array}{l}\text { Identificação } \\
\text { da Notícia }\end{array}$ & Tífulo da Notícia & Data & Fonte de Informação & $\begin{array}{l}\text { Dados Principais } \\
\text { da Notícia }\end{array}$ \\
\hline N1 & $\begin{array}{l}\text { A lição do Recife para o } \\
\text { mundo }\end{array}$ & $04 / 01$ & $\begin{array}{l}\text { Oficial (Secretaria } \\
\text { Municipal de Saúde) }\end{array}$ & $\begin{array}{l}\text { Afonso Bezerra, } \\
\text { Vida urbana, } 3 \\
\text { páginas, foto }\end{array}$ \\
\hline N2 & $\begin{array}{l}\text { Epidemia cresce } 88 \% \text { na } \\
\text { semana }\end{array}$ & $11 / 02$ & $\begin{array}{l}\text { Oficial (Secretaria } \\
\text { Executiva Municipal de } \\
\text { Vigilância à Saúde) }\end{array}$ & $\begin{array}{l}\text { Alice de Souza, } \\
\text { Vida urbana, } 3 \\
\text { páginas, foto }\end{array}$ \\
\hline N3 & $\begin{array}{l}\text { HR investiga morte de } \\
\text { supervisora infectada por } \\
\text { Dengue, Chikungunya ou } \\
\text { Zika }\end{array}$ & $23 / 02$ & $\begin{array}{l}\text { Oficial } \\
\text { (Hospital/Secretaria } \\
\text { Estadual de Saúde) }\end{array}$ & $\begin{array}{l}\text { Sem assinatura, } \\
\text { Vida urbana, } 2 \\
\text { páginas, foto }\end{array}$ \\
\hline N4 & $\begin{array}{l}\text { UPE inicia ciclo de } \\
\text { palestras sobre } \\
\text { Chikungunya, Zika e } \\
\text { Dengue }\end{array}$ & $03 / 03$ & $\begin{array}{l}\text { Oficial (Universidade } \\
\text { Estadual) }\end{array}$ & $\begin{array}{l}\text { Sem assinatura, } \\
\text { Vida urbana, } 1 / 2 \\
\text { página, ausente }\end{array}$ \\
\hline N5 & $\begin{array}{l}\text { Geografia do Aedes } \\
\text { aegypti intriga } \\
\text { especialistas }\end{array}$ & $07 / 03$ & $\begin{array}{l}\text { Oficial (Secretaria } \\
\text { Executiva Municipal de } \\
\text { Vigilância à Saúde) e } \\
\text { Professores Universitários }\end{array}$ & $\begin{array}{l}\text { Alice de Souza, } \\
\text { Vida urbana, } 10 \\
\text { páginas, foto }\end{array}$ \\
\hline N6 & $\begin{array}{l}\text { Combate à Dengue na } \\
\text { comunidade Campo do } \\
\text { Onze, em Santo Amaro }\end{array}$ & $18 / 03$ & $\begin{array}{l}\text { Oficial (Secretaria de } \\
\text { Saúde Municipal) }\end{array}$ & $\begin{array}{l}\text { Sem assinatura, } \\
\text { Vida urbana, } 1 / 2 \\
\text { página, ausente }\end{array}$ \\
\hline
\end{tabular}


A notícia com maior conteúdo (N5), é do tipo editorial, onde dá voz a diversas autoridades e instituições, como a Prefeitura do Recife, Fundação Oswaldo Cruz (Fiocruz), Companhia Pernambucana de Saneamento (Compesa), Empresa de Manutenção e Limpeza urbana (Emlurb) e professores das principais universidades do estado de Pernambuco.

No quadro 1, cada pergunta representa uma categoria temática. A mais frequente foi o papel das autoridades (3 notícias), seguido por informações epidemiológicas (2 notícias), ações educativas promovidas (2 notícias) e culpabilização da comunidade (1 notícia). A categoria temática 4 , formas de prevenção e controle do vetor, não foi abordada em nenhuma das 06 notícias veiculadas pelo jornal online durante o período de estudo.

A partir da análise de conteúdo serão apresentadas as frequências das respostas extraídas para cada categoria temática (pergunta).

Para a categoria temática I, três respostas foram extraídas das notícias encontradas. Dessas três, uma considera que "o município deu uma lição ao mundo em como foi rápido e transparente durante a epidemia da Dengue, diz secretário de saúde".

Em uma entrevista com o Secretário de Saúde do Município para falar sobre a epidemia que ocorreu ao final de 2015, ele explicita como o município deu uma lição ao mundo em como foi rápido e transparente durante a epidemia da Dengue. Além de elogiar os convênios realizados com o governo do estado para o enfretamento da epidemia e os novos investimentos para que ocorra a diminuição das notificações no ano de 2016.

Para a categoria temática II, duas respostas foram extraídas. Uma delas ressalta os dados epidemiológicos, "mesmo sem considerar o período de carnaval, houve um crescimento de $88 \%$ nas notificações de arboviroses na cidade em uma semana. Até então, foram notificados 1.412 casos de arboviroses no Recife, dos quais 744 de Dengue. Os distritos sanitários 5 , 6 e 4 são os que concentram a maior parte das notificações, $46,2 \%$ delas. Nos últimos 10 anos, mesmo aqueles de epidemia, os meses de janeiro, fevereiro e março sempre tiveram aumento dos casos acima do limite esperado".
Praticamente, toda a matéria onde foi extraída a resposta é referente às estatísticas do número de casos notificados.

Para a categoria temática III, apenas uma resposta foi extraída, "os cidadãos têm uma parcela de culpa nos casos de Dengue, os números não negam, $90 \%$ dos focos do Aedes aegypti estão dentro das residências". O trecho foi extraído da notícia "Geografia do Aedes aegypti intriga especialistas", que é uma notícia do tipo editorial assinada pela jornalista Alice de Souza, que tenta realizar uma análise sobre a geografia do Aedes aegpyti. ao longo do material vários especialistas e autoridades falam sobre saneamento básico, planejamento urbano, moradia e desigualdade social.

Para a categoria temática $V$, duas respostas foram extraídas, uma delas é sobre a realização de uma ação de educação em saúde sobre Dengue em uma comunidade de Santo Amaro, uma das regiões com maior número de casos notificados de Dengue durante o período de estudo, "a comunidade Campo do Onze, em Santo Amaro, Recife, recebeu nesta quinta e sexta-feira uma ação de combate ao mosquito Aedes aegypti da Secretaria de Saúde do Recife. Os moradores participaram de uma palestra sobre a importância de evitar os criadouros do vetor da Dengue, os Agentes de Saúde Ambiental e Controle de Endemias (ASACES) visitaram cerca de 250 imóveis. Também foi feita orientação e distribuição de material educativo".

\section{Discussão}

Nesta pesquisa foi possível identificar que mesmo diante de uma epidemia persistente como dengue há escassez de notícias veiculadas pelo jornal online. Entretanto, os achados deste trabalho podem contribuir para o entendimento da dinâmica da comunicação sobre Dengue em Recife. Os estudos em comunicação e saúde apontam que grande parte das notícias sobre dengue são publicadas em períodos sazonais, neste caso, no período de janeiro a abril, justificado pelo período de transmissão da doença pelo mosquito Aedes aegypti, que se multiplica no período das chuvas, durante a estação do verão (Lindner, 2011 ). 
Com isso, no período em que a Dengue afeta um grande número de pessoas, o jornal online se encarregou de informar os novos casos da doença ou óbito, causas da epidemia, além de matérias com os gestores do município. $O$ jornal, ao tratar desses temas predominantemente nesses períodos, priorizando apenas o momento de grande ocorrência da doença, não se compromete com as ações de prevenção que são importantíssimas no decorrer de todo o ano.

Em relação às fontes de informação, os resultados ressaltam a busca por fontes oficiais, como Governo, Secretária de Saúde, Prefeitura do Recife, as Universidades. As fontes oficiais por representarem instituições de poder e exercerem também certo controle e responsabilidades, são as primeiras a serem procuradas pelos jornalistas, ficando em segundo plano os representados, os que não têm a influência de uma autoridade, os que não possuem um cargo representativo.

Há, portanto, um conjunto de razões que levam as fontes não-oficiais a terem pouco ou nenhum espaço para sua representação junto à opinião pública. Os gestores são responsáveis por quase $100 \%$ das matérias, na maioria, divulgando ações desenvolvidas ou repercutindo outras situações em relação aos casos da doença (Lindner, 2011 ).

Já em relação aos resultados encontrados para a classificação das notícias segundo o tema abordado nos títulos e nos textos das matérias, considerando o enfoque dado pelo noticiário a partir da análise de conteúdo, constata- se que o jornal privilegiou temas relacionados aos "número de casos" e o "papel das autoridades perante os casos".

Em nenhuma das seis notícias catalogadas, durante a cobertura da Dengue no período com o maior número de casos, não ocorreu uma preocupação em alertar à população sobre os sinais, sintomas e as formas de prevenção da doença. Como apresentado, seis notícias foram coletadas durante o período de estudo, de acordo com o quadro 1, que analisa através das categorias temáticas e das perguntas formuladas o conteúdo das notícias, foi possível observar que nenhuma categoria temática foi abordada em todas as notícias ao mesmo tempo. E que apesar de duas matérias narrarem ações educati- vas, todas são já promovidas e narradas a partir da voz do gestor público e de instituições. No entanto, os gestores ainda pautam pouco de forma positiva e ativa as ações na mídia. A grande maioria da participação está ligada a repercussões de fatos ou pontos de vista oficiais sobre alguma situação.

O fato de poucas notícias serem veiculadas, e entre elas praticamente todas só narrarem o papel das autoridades e informar dados epidemiológicos, nos leva a repensar a forma de fazer comunicação e de utilizá-la a favor da educação em saúde e do povo. O mecanismo de redução da doença requer a adoção de políticas integradas entre diversos setores e não apenas da saúde. Por isso, falar em saúde na mídia é uma maneira de forjar estratégias que levem o sujeito a adquirir ferramentas que o ajudem a melhorar sua qualidade de vida (Silva \& Rasera, 2011).

É essencial o comprometimento dos profissionais de informação e dos veículos de comunicação para que esta seja utilizada de uma forma social, pois através do seu grande espectro de alcance pode-se levar informações a população sobre as formas de prevenção da dengue, ações de controle do vetor, e principalmente ajudar na elevação da consciência coletiva, de que cada um pode ser um agente protagonista na mobilização para minimizar o número de casos da doença (Silva, Cardoso, Mulatinho, Souza, \& Júnior 2017).

Segundo Villela e Natal (2014), devido às falhas na educação em saúde já apresentadas, passa a ser fundamental reposicionar os meios de comunicação, para que participe do processo de comunicação e informação em saúde, informando a população. A mídia é vista na atualidade como um importante meio de veiculação de informações em saúde.

\section{Considerações finais}

Em uma visão ampliada, válida para qualquer doença, os estudos sobre a comunicação, a mídia e a saúde, são extremamente importantes, para que se abra uma discussão em torno de como as informações circulam e são apropriada. É importante debater que tipo de informação o cidadão tem 
acesso durante os processos epidêmicos, mas também durante todo o ano. É neste contexto que tipos de estudo como este podem contribuir na área da saúde pública. $O$ estudo apresenta como limitações uma pequena amostra, pois o número de jornais disponíveis foi pequeno, devido às dificuldades de conseguir as notícias através do site e do Escritório de Redação do Jornal. Porém a riqueza do tema e a complexidade do objeto estudado não se esgotam neste trabalho, ficando abertas possibilidades futuras de continuidade ou ampliação dos pontos de vista.

\section{Limitações}

Não foi possível ter uma amostra maior através de mais jornais de Recife, devido as dificuldades de conseguir as notícias através do site e do Escritório de Redação dos outros dois jornais mais acessados no município, porém a riqueza do tema e a complexidade do objeto estudado não se esgotam neste trabalho, ficando abertas possibilidades futuras de continuidade ou ampliação dos pontos de vista, através de outras análises ou amostras.

\section{Conflitos de interesses}

Nenhum conflito financeiro, legal ou político envolvendo terceiros (governo, empresas e fundações privadas, etc.) foi declarado para nenhum aspecto do trabalho submetido (incluindo mas não limitandose a subvenções e financiamentos, conselho consultivo, desenho de estudo, preparação de manuscrito, análise estatística, etc).

\section{Referências}

Bardin, L. (2009). Análise de conteúdo. Lisboa, Portugal: Edições 70.

Ferreira, W. (2006). Comunicação e Saúde: estudo de caso das notícias sobre malária e dengue publicadas no Jornal Folha de Boa Vista (Trabalho de conclusão de curso). Universidade Federal de Roraima: Boa Vista, RR, Brasil.

França, E., Abreu, D., \& Siqueira, M. (2004). Epidemias de dengue e divulgação de informação pela imprensa. Cadernos de Saúde Pública, 20(5), 1334-1341. Recuperado de https://scielosp.org/pdf/csp/2004. v20n5/1334-1341/pt. doi: 10.1590/S0102$\underline{311 \times 2004000500028}$
Gerhardt, T. E., \& Silveira, D. T. (2009). Métodos de pesquisa. Porto Alegre: Editora da UFRGS.

Instituto Trata Brasil. (2016). Ranking do saneamento: avaliação dos serviços nas 100 maiores cidades brasileiras 2014 . Recuperado de http://www. tratabrasil.org.br/datafiles/estudos/ranking/ relatorio-completo-2014.pdf

Lindner, L. C. (2011). Quem fala, o que fala e como fala Conceitos, percepções e representações de saúde e doença na mídia: $O$ caso da Tuberculose (Dissertação de mestrado). Fundação Oswaldo Cruz, Rio de Janeiro, RJ, Brasil. Recuperado de http://www6.ensp. fiocruz.br/radis/sites/default/files/113/dissertacao_ final_para_defesal.pdf

Ministério da Saúde. (2014). Guia de vigilância em saúde. Brasília: Ministério da Saúde. Recuperado de http:// bvsms.saude.gov.br/bvs/publicacoes/guia_vigilancia_ saude_unificado.pdf

Ministério da Saúde. (2017). Boletim epidemiológico, 48(2). Recuperado de http://portalsaude.saude.gov.br/ images/pdf/2017/ianeiro/12/2017_001\%20-\%20 Dengue\%20SE5 1 _publicacao.pdf

Mozzato, A. R., \& Grzybovski, D. (2011). Análise de conteúdo como técnica de análise de dados qualitativos no campo da administração: potencial e desafios. Revista de Administração Contemporânea, 15(4), 731-747. Recuperado de http://www.scielo.br/pdf/rac/v15n4/ a $10 v 15 n 4 . p d f$

Pimenta, D. N. (2008). Disseminação de informação sobre dengue: o ergodesign no desenvolvimento e avaliação de material de multimídia para educação em saúde (Tese de doutorado). Centro de Pesquisa René Rachou, Fundação Oswaldo Cruz, Belo Horizonte, MG, Brasil. Recuperado de http://www.cpqrr.fiocruz.br/textocompleto/T_14.pdf

Romano, T. J. C., Cibotto, B. M. L., Velho, A. P. M., \& Lucena, T. F. (2015). Dengue na imprensa local: Uma doença em notícia. Anais Encontro Internacional de Produção Científica UniCesumar, Paraná, PR, Brasil, 9. Recuperado de http://www.cesumar.br/prppge/ pesquisa/epcc2015/anais/talita_joana_casagrande_ romano_1.pdf

Santana, B. C. S., \& Temer, A. C. R. P. (2014). Televisão e saúde: Os temas ligados à qualidade de vida no telejornal J.A. primeira edição da TV Anhanguera. Revista Panorama, 4(1), 39-50. Recuperado de http:// seer.pucgoias.edu.br/index.php/panorama/article/ view $/ 3459 / 2028$ 
Santos, S. L., Costa e Silva, M. B., Cabral, A. C. S. P., Gonçalves, G. M. S., \& Augusto, L. G. S. (2015). Percepção sobre o controle da dengue: uma análise a partir do discurso coletivo. Revista Movimentos Sociais e Dinâmicas Espaciais, 4(2), 115-130. Recuperado de https://periodicos.ufpe.br/revistas/revistamseu/ article/view/229883/24088

Secretaria de Comunicação Social da Presidência da República. (2015). Pesquisa brasileira de mídia 2015: Hábitos de consumo de mídia pela população brasileira. Brasília: Autor. Recuperado de http://www. secom.gov.br/atuacao/pesquisa/lista-de-pesquisasquantitativas-e-qualitativas-de-contratos-atuais/ pesquisa-brasileira-de-midia-pbm-2015.pdf

Secretaria Executiva de Vigilância à Saúde. (2016). Boletim epidemiológico. Recuperado de https:// cievsrecife.files.wordpress.com/2012/08/boletim-dearboviroses-se-52-1.pdf

Silva, G. M., \& Rasera, E. F. (2011). A construção do SUSproblema no jornal Folha de S. Paulo. História, Ciências, Saúde- Manguinhos, 21(1), 1-15. Recuperado de http://www.scielo.br/pdf/hcsm/v2 1n 1/01045970-hcsm-S0104-59702013005000012.pdf. doi: $10.1590 / \mathrm{S} 0104-59702013005000012$

Silva, I. B., Mallmann, D. G., \& Vasconcelos, E. M. R. (2015). Estratégias de combate à dengue através da educação em saúde: Uma revisão integrativa. Revista Saúde Santa Maria, 41 (2), 27-34. Recuperado de https://periodicos.ufsm.br/revistasaude/article/ view/10955/pdf_1

Silva, Y. R. M., Cardoso, M. D., Mulatinho, L. M., Souza, C. F. Q. S., Júnior, W. S. S. (2017). O que se noticia sobre dengue em Recife, Brasile. Atas do Congresso IberoAmericano em Investigação Qualitativa em Saúde, Salamanca, SL, Espanha, 6. Recuperado de http:// proceedings.ciaiq.org/index.php/ciaiq2017/article/ view $/ 1278 / 1238$

Villela, E. F. M. (2012). Representações sociais sobre dengue na mídia impressa: Informação epidemiológica, educativa ou política? (Tese de doutorado). Faculdade de Saúde Pública, Universidade de São Paulo, São Paulo, SP, Brasil. Recuperado de http://www.teses.usp.br/teses/ disponiveis/6/6132/tde-01102012-161911/pt-br. php

Villela, E. F. M., \& Natal, D. (2014). Mídia, saúde e poder: Um jogo de representações sobre dengue. Saúde e Sociedade, 23(3), 1007-1017. Recuperado de http://www.scielo.br/pdf/sausoc/v23n3/01041290-sausoc-23-3-1007.pdf. doi: 10.1590/s010412902014000300022
Xavier, L. L. (2010). Elaboração de uma ferramenta lúdica sobre o tema dengue utilizando linguagem computacional (Tese de mestrado). Instituto Oswaldo Cruz, Rio de Janeiro, RJ, Brasil. Recuperado de https://www.arca.fiocruz.br/handle/icict/4051 